National Center for Family \& Marriage Research

@ Bowling Green State University

Family Profile No. 1, 2022

Trends in Non-Marriage Among Men, 2005-2019

Author: Adrianne R. Brown \& Karen B. Guzzo

Marital behavior has changed dramatically in the U.S. (FP-21-24), with variation across sociodemographic characteristics such as education and race-ethnicity (FP-21-12). Using data from the American Community Survey (ACS), this profile examines the share of never-married men aged 35-39 by race-ethnicity and educational attainment. We focus on those aged 35-39 because this age bracket is above the median age of first marriage (the age in which at least $50 \%$ of men were married) in 2019 (FP-21-12) and captures most first marital experiences. White, Black, and Asian refers to those who are non-Hispanic and report a single race in the ACS, and Hispanic refers to those who report their ethnicity as Hispanic, regardless of race. Those with a two-year degree are included in the "some college" category.

- Overall, the share of men aged 35-39 who had never married was 32\% in 2019, up from $21 \%$ in 2005 (not shown). The educational disparities among never married men have widened over this time span.

\section{White Men}

- In 2005 , the education gradient in marriage was quite narrow. About one in five (22\%) of White men aged 35 39 in the lowest education category-H.S. diploma or less - had never married, compared to $17 \%$ in the highest education category-post-graduate degree.

- Between 2005 and 2019, the greatest change occurred among those with modest educational attainment. The share of never-married White men aged 35-39 with a H.S. diploma or less increased substantially to nearly two-fifths.

- In contrast, there was little change among those with the highest education levels. In 2019, 18\% of men with a post-graduate degree remained unmarried.

Figure 1. Share of Never-Married White Men Aged 35-39 by Education, 2005-2019

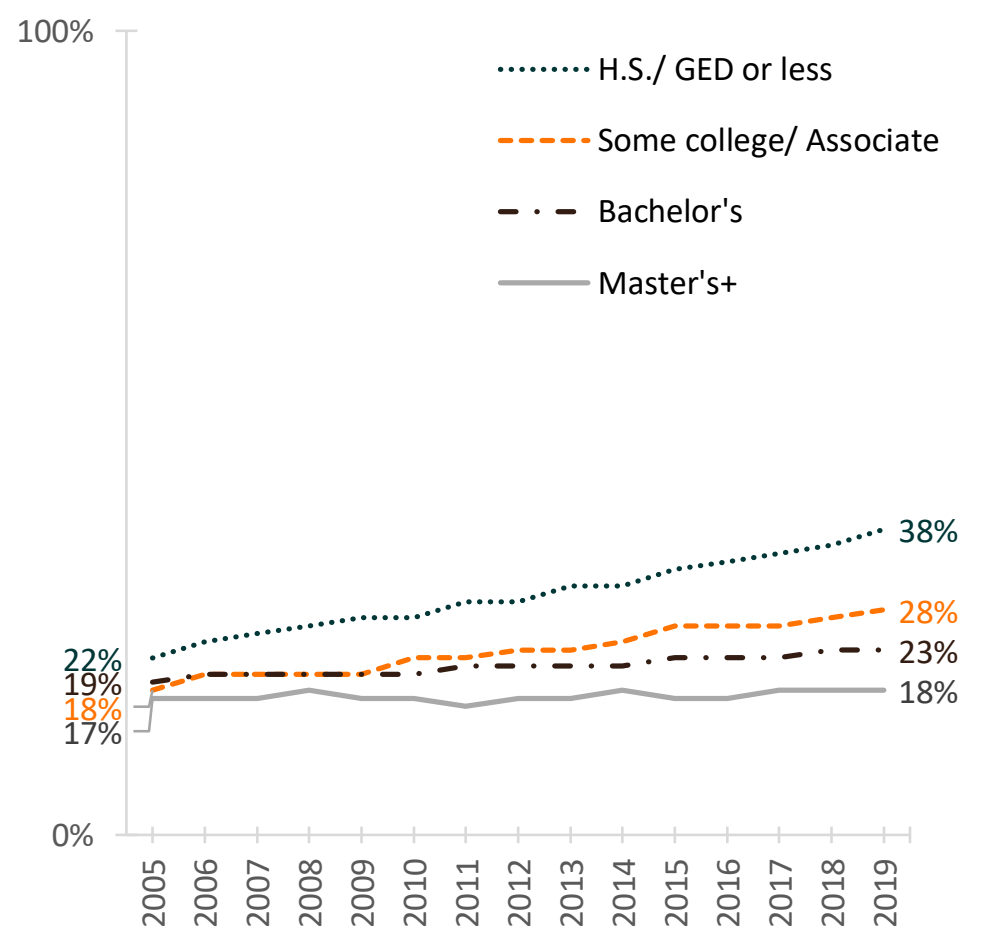

Black Men

- In 2005, nearly two-fifths of Black men aged 35-39 with a H.S. diploma or less had never married, compared to just one-fifth of those with a post-graduate degree.

- Between 2005 and 2019, the share of Black men who never married rose to $57 \%$ among those with a H.S. diploma or less, but the largest absolute increase was among those with some college, rising from $26 \%$ to $48 \%$.

- Conversely, those with a bachelor's degree but no postgraduate degree had the smallest change $-36 \%$ had never been married in 2019, up from 29\% in 2005.

Figure 2. Share of Never-Married Black Men Aged 35-39 by Education, 2005-2019

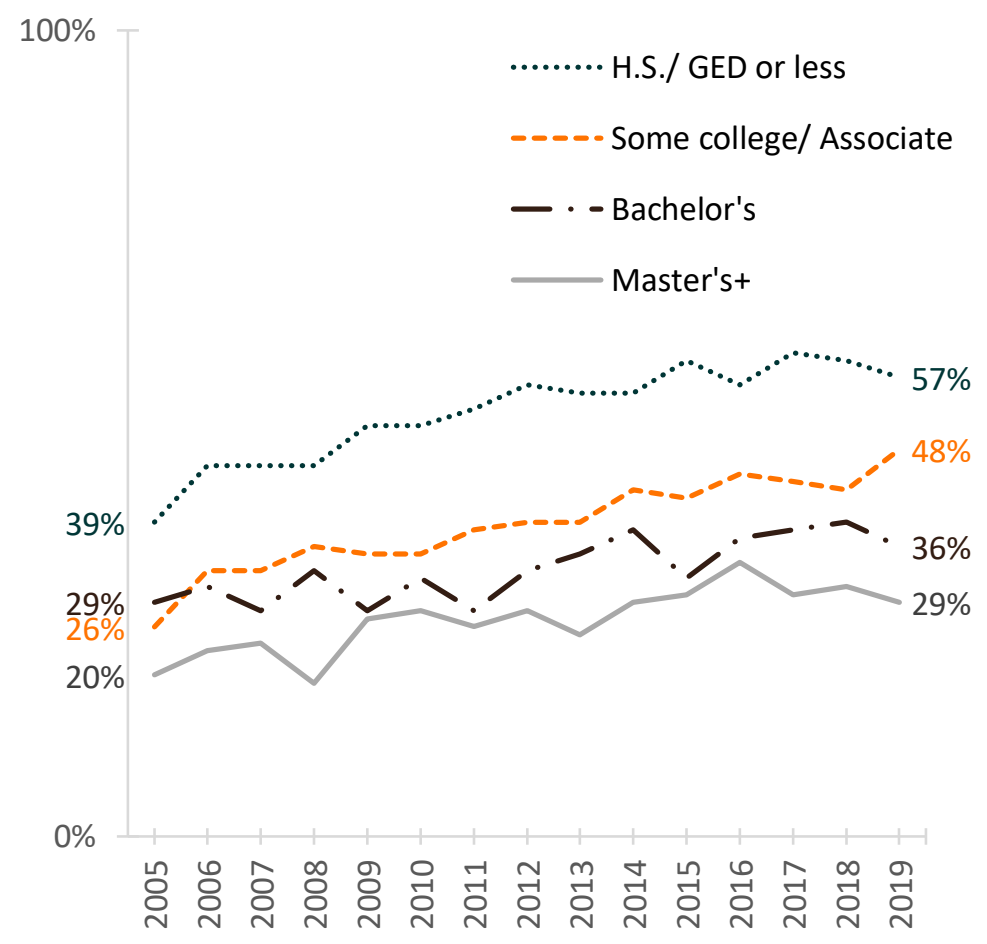


Hispanic Men

- In 2005, among Hispanic men aged 35-39, there were few differentials in marriage by education level. The largest share never married was $26 \%$ among those with a bachelor's degree, whereas the smallest share was $18 \%$ among those with a post-graduate degree.

- Between 2005 and 2019, the share of unmarried Hispanic men increased among all educational attainment groups. The largest increase was among those with a H.S. diploma or less.

- The smallest change occurred among those with a postgraduate degree; in 2019, 22\% had never married.

Figure 3. Share of Never-Married Hispanic Men Aged 35-39 by Education, 2005-2019

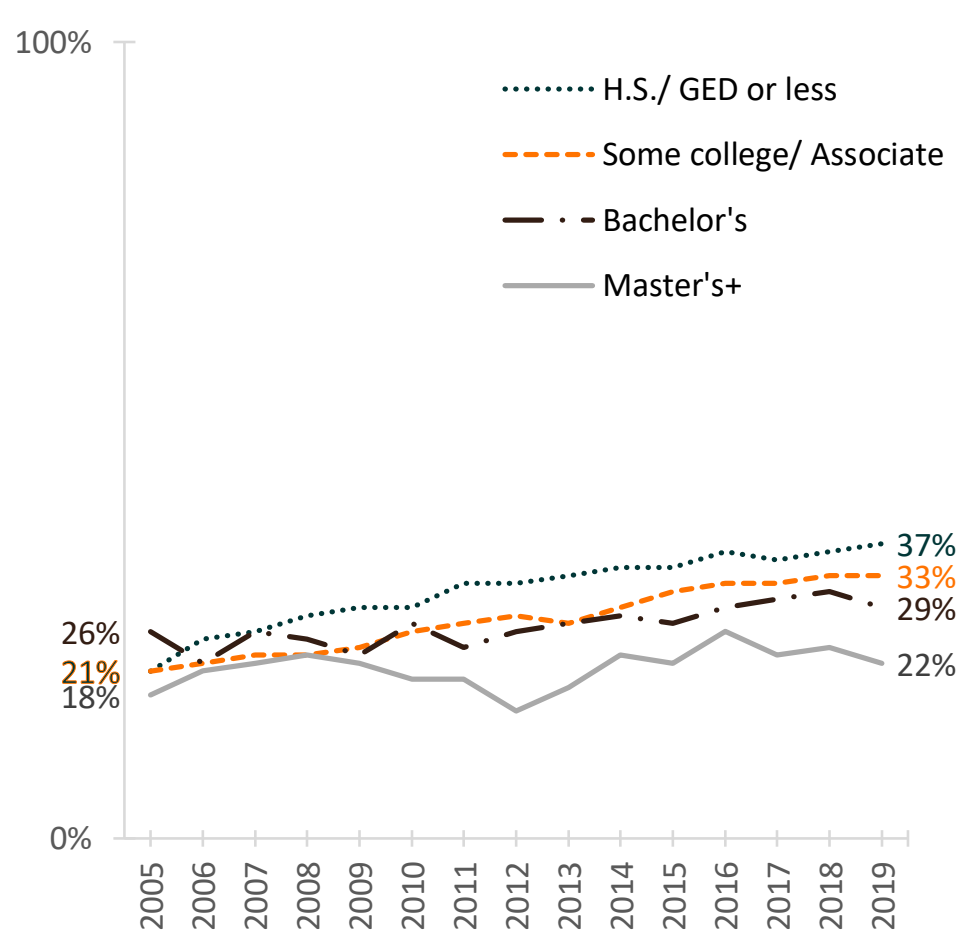

Asian Men

- In 2005, the share of never-married Asian men aged 3539 was about $20 \%$ among those without a post-graduate degree. Only $12 \%$ of men with a post-graduate degree had not married in 2019.

- Between 2005 and 2019, the share never married increased the most among those with some collegefrom $20 \%$ in 2005 to $34 \%$ in 2019.

- The smallest increase was found among those with a post-graduate degree. Their share only increased to $14 \%$ in 2019.

Figure 4. Share of Never-Married Asian Men Aged 35-39 by Education, 2005-2019

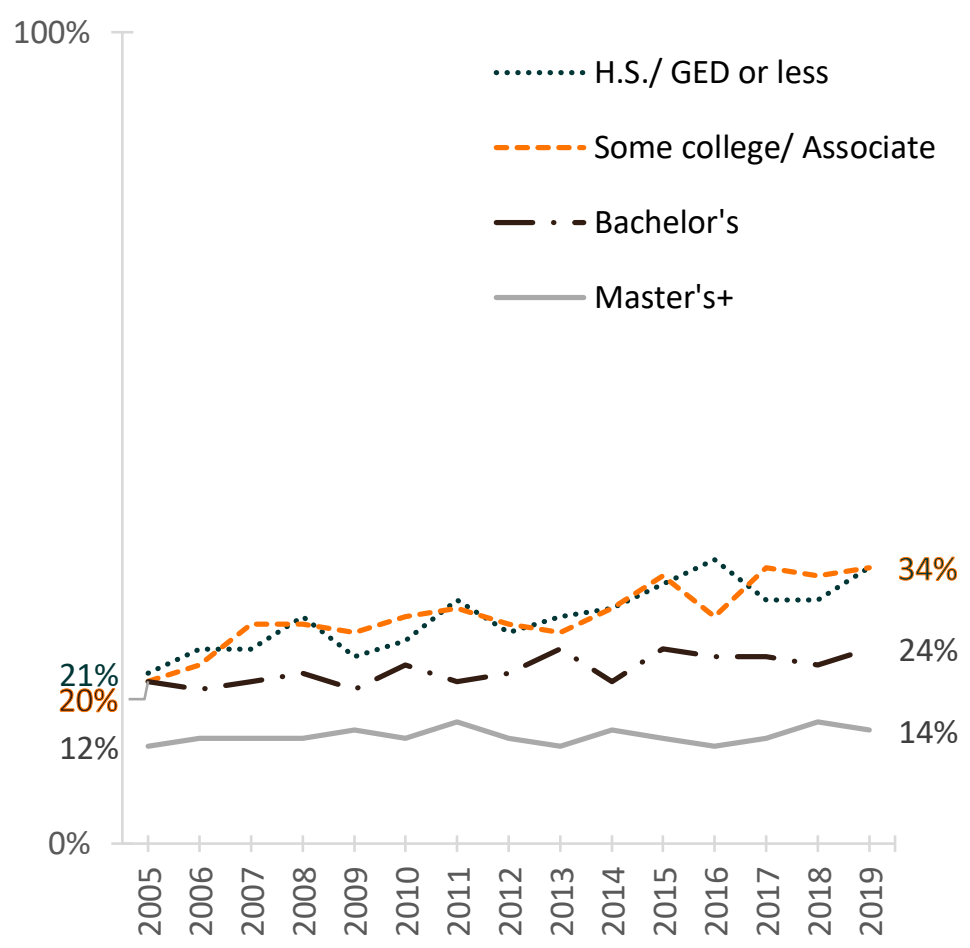

Source: NCFMR analyses of the American Community Survey 1-year estimates, 2005-2019

\section{Data Source:}

Ruggles, S. Flood, S., Foster, S., Goeken, R., Pacas, J., Schouweiler, M., \& Sobek, M. (2021). IPUMS USA: Version 11.0 [dataset]. Minneapolis, MN: IPUMS. https://doi.org/10.18128/D010.V11.0

\section{References:}

Payne, K. K. (2019). Median age at first marriage, 2019. Family Profiles, FP-21-12. Bowling Green, OH: National Center for Family \& Marriage Research. https://doi.org/10.25035/ncfmr/fp-21-12

Payne, K. K. (2021). Marital experiences in the U.S., 1996 \& 2018. Family Profiles, FP-21-24. Bowling Green, OH: National Center for Family \& Marriage Research. https://doi.org/10.25035/ncfmr/fp-21-24

\section{Suggested Citation:}

Brown, A. R. \& Guzzo, K. B. (2022). Trends in Non-Marriage Among Men, 2005-2019. Family Profiles, FP-22-01. Bowling Green, OH: National Center for Family \& Marriage Research. https://doi.org/10.25035/ncfmr/fp-22-01 